\title{
APERSEPSI PEMBELAJARAN MELALUI STAND-UP COMEDY UNTUK MENINGKATKAN MOTIVASI BELAJAR MAHASISWA DENGAN METODE CERAMAH DI STKIP PGRI PONOROGO
}

\author{
Rizki Mustikasari \\ Ratri Harida \\ STKIP PGRI Ponorogo \\ e-mail: \\ mustikasaririzki@gmail.com; ratri3rida@gmail.com
}

\begin{abstract}
Abstrak: Penelitian ini merupakan penelitian eksperimen dengan dua kelompok sampel yang menguji penggunaan stand-up comedy dalam apersepsi pembelajaran untuk meningkatkan motivasi belajar mahasiswa dengan metode ceramah. Metode pembelajaran ceramah adalah metode yang paling banyak digunakan oleh dosen untuk menyampaikan materi perkuliahan, tetapi metode ini seringkali membuat mahasiswa menjadi jenuh dan kurang termotivasi dalam belajar. Motivasi belajar mahasiswa harus dibangun sejak dosen melakukan apersepsi di kelas. Beberapa peneliti mengemukakan bahwa joke dan cerita lucu dapat meningkatkan motivasi belajar peserta didik. Stand-up comedy adalah bentuk humor oleh satu orang penampil menggunakan monolog. Humor gaya ini saat ini sedang banyak diminati oleh kaum muda termasuk mahasiswa. Penelitian dalam bentuk eksperimen ini melibatkan 40 mahasiswa dalam 2 kelompok, kontrol dan eksperimen. menggunakan model stand-up comedy untuk menyampaikan pesan pembelajaran di dalam kela Temuan menunjukkan bahwa apersepsi pembelajaran melalui stand-up comedy dalam metode ceramah secara signifikan dapat meningkatkan minat belajar mahasiswa.
\end{abstract}

Kata kunci: stand-up comedy, apersepsi stand-up comedy, stand-up comedy untuk pembelajaran

\section{LEARNING APERSEPTION THROUGH STAND-UP COMEDY TO IMPROVE STUDENT'S LEARNING MOTIVATION WITH THE LIGHTING METHOD AT STKIP PGRI PONOROGO}

\begin{abstract}
This study was an experimental study with two sample groups to examine the use of stand-up comedy in learning aperceptions to increase student's learning motivation using lecture method. The lecture method is the most widely used by lecturers to deliver the material, but this method often makes students bored and less motivated in learning. Students' learning motivation must be built since the beginning of the class using aperceptions. Some researchers suggest that jokes and funny stories can increase students' motivation to learn. Stand-up comedy is humor performed by a monologue performer. This humor is favored by young people including students. This experimental study involved 40 students in two groups; control and experiment. The finding showed that learning aperception through stand-up comedy model in lecture method can significantly improved students' learning motivation.
\end{abstract}

Keywords: stand-up comedy, apperception, humor for learning, student motivation 


\section{PENDAHULUAN}

Metode ceramah adalah metode pembelajaran yang paling tua dan paling banyak digunakan oleh para pengajar, termasuk dosen. Karena berbagai alasan, metode ceramah masih eksis hingga saat ini. Walaupun banyak penelitian tentang metode-metode baru yang lebih efektif, namun pada matakuliah dan materi-materi tertentu metode ceramah masih dirasa paling sesuai untuk digunakan, meskipun metode ceramah memiliki beberapa kekurangan. Salah satu kekurangannya adalah kurang menarik bagi peserta didik. Penyampaian materi yang hanya terpusat pada guru sebagai sumber informasi sering kali membuat peserta didik menjadi bosan, sehingga meskipun secara fisik mereka tampak memperhatikan, namun sesungguhnya yang mereka pikirkan bukan apa yang disampaikan oleh pengajarnya. Kondisi pembelajaran semacam ini terjadi hingga tingkat universitas. Mahasiswa sering mengalami kebosanan saat dosen menggunakan metode ceramah.

Dosen STKIP PGRI Ponorogo masih banyak yang memilih metode ceramah dalam proses pembelajarannya. Hal tersebut dilakukan mengingat sebagian besar prodi di STKIP PGRI Ponorogo merupakan program studi kebahasaan, sehingga mau tidak mau dosen menerapkan metode ceramah. Penerapan metode ini sering membuat mahasiswa menjadi bosan, dan kurang termotivasi dalam belajar, oleh sebab itu dosen berusaha memberi apersepsi yang menarik pada awal kuliah agar mahasiswa menjadi lebih termotivasi mengikuti mata kuliah. Apersepsi adalah jembatan awal menuju penyampaian materi dalam suatu proses pembelajaran. Keberhasilan dalam melakukan apersepsi sangat menentukan keberhasilan pembelajaran pada setiap pertemuannya. Apersepsi sebisa mungkin harus diawali dari pengalaman mahasiswa, sehingga mahasiswa secara kognitif terlibat dalam apersepsi tersebut.

Mengutarakan pengalaman dengan cara yang menyenangkan salah satunya adalah dengan menggunakan humor. Dosen dapat mengutarakan keresahan atau mengangkat pengalaman yang dekat dengan mahasiswa, dimana keresahan dan pengalaman tersebut berhubungan dengan materi yang akan disampaikan dengan cara jenaka. Kegiatan semacam ini dalam dunia pentas hiburan disebut dengan Stand-up comedy. Mengacu pada uraian tersebut, maka penelitian ini dilakukan untuk mengkaji apa dan bagaimana apersepsi pembelajaran melalui stand-up comedy meningkatkan minat belajar mahasiswa dengan metode ceramah.

Metode pembelajaran ceramah berasal dari bahsa latin lecturu yang berarti membaca. Pengertian tersebut secara umum diterjemahkan sebagai guru yang menyampaikan pelajaran dengan membaca dari buku, kemudian mendikte materi pelajaran tersebut kepada siswa secara utuh seperti yang terdapat di buku (Gilstrap dan Martin:1975:125). Abuddin (2011:181-182) memberikan pegertian tentang metode ceramah adalah penyampaian pelajaran yang dilakukan oleh guru dengan penuturan atau penjelasan lisan secara langsung di hadapan peserta didik. Menurut Nizar dan Hasibuan (2011:58), metode ceramah dilakukan di depan beberapa orang pesertadidik dengan bahasa lisan, sedangkan peserta didik hanya mendengarkan penjelasan materi yang disampaikan.

Metode ceramah diawali dengan merumuskan tujuan khusus yang akan dipelajari oleh peserta didik, kemudian pendidik menyusun bahan ceramah. Bahan ceramah yang digunakan harus dapat membangkitkan minat dan menarik bagi 
peserta didik. Agar menarik minat peserta didik, bahan ceramah harus disesuaikan dengan taraf perkembangan peserta didik, lingkungan sosial, serta budaya sekitarnya. Selain itu pendidik juga harus merancang tentang penggunaan bahasa, tempo berbicara, serta mimik yang akan digunakan saat melakukan pembelajaran dengan metode ceramah.

Pelaksanaan pembelajaran dengan metode ceramah dimulai dengan melakukan penyesuaian bahan baru yang akan diajarkan dengan pengetahuan yang telah dimiliki peserta didik atau disebut dengan apersepsi (Sriyono $d k k: 1992: 83$ ). Apersepsi punya kedudukan penting dalam kegiatan pembelajaran (Munif: 2011:77). Adapun tujuan dari apersepsi adalah untuk menarik peserta didik ke dunia yang pendidik ciptakan, menyatukan dua dunia, dan menciptakan atmosfir pembelajaran (Shiril: 2012). Apersepsi bisa dilakukan dengan mengingatkan peserta didik pada pengetahuan yang telah mereka miliki, kemudian membandingkan pengetahuan lama (materi lama) tersebut dengan yang akan disajikan. Hal tersebut dapat dilakukan jika materi yang akan disampaikan berkaitan dengan materi sebelumnya, atau materi yang telah disampaikan. Jika materi yang akan disampaikan tidak berhubungan dengan materi sebelumnya, pendidik bisa memulai apersepsi dengan menghubungkan materi pelajaran dengan hal-hal umum yang dekat dengan peserta didik (Abdul:2013:245).

Apersepsi dapat membuat materi baru mudah diterima, memberikan warna pada materi baru melalui materi atau pengalaman terdahulu sehingga menjadi satu kesatuan yang integral, menumbuh kembangkan ketertarikan (interest) dan perhatian (attention) peserta didik dalam belajar, memunculkan keterbukaan pada peserta didik untuk menerima pengalaman atau materi baru, dan menumbuhkan kembangkan motivasi belajar (Eriawati: 2017: 97-108). Motivasi adalah perubahan energi dalam diri seseorang yang ditandai dengan timbulnya perasaan dan reaksi untuk mencapai tujuan (Oemar:2011:158). Motivasi seseorang dapat diidentifikasi dari ketekunan menghadapi tugas, keuletan menghadapi kesulitan, minat terhadap berbagai masalah, minat untuk bekerja mandiri, tidak cepat bosan pada tugas-tugas rutin, kemampuan mempertahankan pendapat, kegigihan mempertahankan hal yang diakini, dan senang memecahkan berbagai persoalan (Sardiman:2011:83-84). Sukadi (2006:87) berpendapat bahwa iklim belajar yang menyenangkan dapat meningkatkan motivasi belajar peserta didik, dan iklim yang menyenangkan salah satunya dapat dibangun melalui komedi.

Penelitian yang dilakukan oleh Hilman Ramdiana (2020:18-28) menemukan bahwa apersepsi menggunakan cerita humor atau cerita lucu terbukti berhasil meningkatkan motivasi belajar peserta didik. Menurut Uno (2011:23) indikator motivasi belajar peserta didik dapat dilihat dari adanya: 1) Hasrat dan keinginan untuk berhasil; 2) Dorongan dan kebutuhan dalam belajar; 3) Harapan dan cita-cita masa depan; 4) Penghargaan dalam belajar; 5) Kegiatan yang menarik dalam belajar; dan 6) Lingkungan belajar yang kondusif. Abdul Rahman $P$, dkk (2020:158-165) dalam artikel ilmiahnya menuliskan bahwa komedi merupakan salah satu materi yang dapat menarik perhatian setiap orang, tak terkecuali peserta didik. Berdasarkan dua penelitian tersebut maka dapat disimpulkan bahwa dengan menggunakan komedi, motivasi belajar peserta didik dapat meningkat karena komedi dapat menciptakan kemenarikan pada materi dan lingkungan belajar yang kondusif. Pendidik yang 
humoris, dan mampu menyuguhkan joke akan lebih mudah diterima. Lebih lanjut juga dijelaskan bahwa apersepsi komedi dapat dilakukan sebagai awal kegiatan pembelajaran, untuk itu pendidik harus terlebih dahulu menyusun naskah. Jika pendidik menggunakan komedi tanpa naskah, hal tersebut tidak dapat disebut komedi melainkan hanya joke-joke spontan yang tidak terstruktur dan tidak dirancang sebagai apersepsi yang terkoneksi dengan materi pelajaran.

Stand-up comedy adalah salah satu jenis seni komedi yang disampaikan secara langsung oleh seorang komedian yang tampil secara tunggal. Meskipun penampilan tersebut disebut stand-up comedy, namun komediannya tidak selalu berdiri saat berkomedi. Ada juga beberapa komedian yang melakukan stand-up comedy dengan duduk seperti sedang bercerita (Nugroho:2012:1). Penelitian Bruno Pinto (2013:1-18) menunjukkan sebagian ilmuwan juga meyakini bahwa stand-up comedy berpotensi untuk mengkomunikasikan sains, berarti stand-up comedy dapat digunakan dalam menyampaikan pesan-pesan pembelajaran sains. Sependapat dengan hal tersebut sebuah studi kasus yang dilakukan dosen di Universitas ELF Vietnam, menunjukkan hasil bahwa komedi dapat meningkatkan motivasi dan ketertarikan untuk menjadi orang yang menguasai banyak bahasa dalam era globalisasi. Dalam studi kasus tersebut, sejumlah 20 dosen menggunakan komedi dalam pembelajaran bahasa Inggris (Petraki:2016).

\section{METODE}

Metode yang digunakan dalam penelitian ini adalah eksperimen dengan menggunakan dua sampel berhubungan. Populasi penelitiannya adalah seluruh mahasiswa STKIP PGRI Ponorogo, sedangkan sampelnya adalah mahasiswa STKIP PGRI Ponorogo Angkatan 2018 pada mata kuliah Metodologi Penelitian. Pada saat penelitian, mahasiswa sampel sedang menempuh semester ke-4 sehingga diasumsikan telah terbiasa dengan kondisi lingkungan kampus. Hal tersebut menjadi perhatian peneliti karena dapat mempengaruhi hasil pengukuran penelitian.

Sampel dibagi dalam dua kelompok, yaitu kelompok kontrol dan kelompok eksperimen. Kelompok kontrol berasal dari mahasiswa prodi Pendidikan Bahasa dan Sastra Indonesia Angkatan 2018 dan mahasiswa Pendidikan Bahasa Inggris Angkatan 2018 sejumlah 20 orang. Kelompok eksperimen berasal dari mahasiswa prodi Pendidikan Bahasa Jawa Angkatan 2018 dan mahasiswa prodi Pendidikan Guru Pendidikan Anak Usia Dini Angkatan 2018 sejumlah 20 orang. Pada kelompok kontrol, dosen memberikan apersepsi secara klasik dengan menggunakan metode pembelajaran ceramah untuk mata kuliah Metodologi Penelitian. Sebelum memulai pembelajaran, dosen menyusun rencana pembelajaran sesuai dengan metode pembelajaran yang dipilih. Apersepsi pembelajaran dimulai dengan mengingatkan mahasiswa tentang materi sebelumnya atau pengalaman yang dekat dengan mahasiswa. Pengalaman tersebut kemudian dikaitkan dengan materi yang akan disampaikan.

Pada kelas eksperimen dosen mengawali penyusunan script stand-up comedy dengan menentukan pokok bahasan utama yang akan disampaikan saat apersepsi. Selanjutnya dosen membuat premis yang berupa perasaan negatif atau sisi paling negatif tentang pokok bahasan tersebut. Premis ini kemudian dipecah 
menjadi beberapa cerita singkat yang menguatkan penggambaran premis tersebut. Dalam penelitian ini pokok bahasan yang dipilih adalah Konsep dasar Penelitian Tindakan Kelas. Premis yang dipilih adalah tipe-tipe mahasiswa saat menentukan judul penelitian Tindakan kelas. Premis tersebut dibagi menjadi lima bagian cerita singkat yaitu: (1) Mahasiswa menyalin judul penelitian dari internet; (2) Mahasiswa mengajukan masalah di kelas yang tidak berhubungan dengan proses belajarmengajar; (3) Mahasiswa tidak tahu apa yang dimaksud masalah dalam penelitian; (4) Mahasiswa memaksakan judul yang dipilih kepada dosen pembimbing padahal judul itu kurang tepat; (5) Mahasiswa yang bimbingan hanya satu kali kemudian tidak pernah kembali lagi.

Setelah menentukan pokok bahasan, premis, dan membagi premis ke dalam cerita-cerita singkat, berikutnya Dosen Menyusun setup dan punchline agar naskah materi stand-up comedy menjadi utuh. Setup adalah pengantar dari sebuah joke, sedangkan punchline adalah bagian lucu dari sebuah joke. Dalam naskah yang disusun dalam penelitian ini, setup dan punchline yang dibuat menggunakan bahasa dan ungkapan yang informal sebagai berikut.

1. Mahasiswa sekarang itu beruntung, apa-apa tinggal tanya google. Ketik "judul PTK", pas keluar banyak banget. Trus diganti lagi "judul PTK terbaru", masih banyak lagi dan masih pusing milihnya. Tambah lagi khawatir kalau ketahuan copas sama dosennya. Akhirnya tanya google "judul PTK terbaru yang gak ketahuan copas sama dosenku", terus yang keluar malah cerpen bucin di kampus.

2. Kalau kita mau buat penelitian tindakan kelas tuh harus berangkat dari masalah yang ada di kelas. Nggak boleh kita tahu-tahu bikin penelitian tindakan kelas tapi sebenarnya nggak nemu masalah di kelas. Kalau kepepetnya kita nggak nemu masalah, ya kita harus bikin masalahnya. Pernah ada mahasiswa lapor ke saya. "Bu saya mau buat PTK tentang siswa yang selalu meninggalkan kelas" saya jawab "ya bagus itu. Di mana itu kejadiannya?" "Di sekolah SMA saya dulu bu, pas jam istirahat suka pada ninggalin kelas dan makan di kantin".

3. Lain hari, lapor lagi mahasiswa lain ke saya. "Bu, setelah saya mendapat penjelasan dari ibu tentang caranya bikin PTK, kayaknya saya nggak usah selesaikan kuliah aja deh bu. Ya saya tanya dong "kenapa begitu?" "Saya nggak mau cari masalah sama orang lain bu".

4. Mahasiswa itu ya, kalau udah disuruh nentuin judul penelitian sikapnya juga aneh-aneh. Ada ini mahasiswa yang maksa minta dilolosin judul PTK-nya sampe datang kerumah bawa minyak goreng sekardus. Judul PTK-nya "Peningkatan kemampuan matematika dengan menambah uang saku dari orang tua" masa iya mau saya loloskan? Jangankan bawa minyak goreng sekardus, bawa pabriknya minyak goreng ditambah pabrik minyak rem juga tetep nggak akan lolos. Jadi tolonglah nurut sama dosen pembimbing.

5. Ada juga sih yang pas pertama kali bimbingan judul, dikasih masukan begini begini, dia jawab "lya bu","oh begitu ya bu", "baik bu". Tapi habis itu gak pernah muncul-muncul lagi orangnya. Gak pernah datang bimbingan lagi. Sampai hampir saya kirimin karangan bunga rumahnya. "Turut berduka cita atas wafatnya semangat anda". 
Mahasiswa pada kelompok eksperimen diberikan apersepsi menggunakan stand-up comedy dengan metode pembelajaran ceramah untuk mata kuliah Metodologi Penelitian Pendidikan. Dosen menyiapkan rencana pembelajaran menggunakan apersepsi dengan stand-up comedy. Selain menyiapkan materi pembelajaran, dosen juga menyiapkan materi stand up yang relevan dengan materi yang akan disampaikan. Materi stand-up comedy disusun dalam bentuk script. Dosen mengawali penyusunan script stand-up comedy dengan menentukan pokok bahasan utama yang akan disampaikan saat apersepsi. Selanjutnya dosen membuat premis yang berupa perasaan negatif atau sisi paling negatif tentang pokok bahasan tersebut. Premis ini kemudian dipecah menjadi beberapa cerita singkat yang menguatkan penggambaran premis tersebut. Dalam penelitian ini pokok bahasan yang dipilih adalah Konsep dasar Penelitian Tindakan Kelas. Premis yang dipilih adalah tipe-tipe mahasiswa saat menentukan judul penelitian Tindakan kelas. Premis tersebut dibagi menjadi lima bagian cerita singkat yaitu: (1) Mahasiswa menyalin judul penelitian dari internet; (2) Mahasiswa mengajukan masalah di kelas yang tidak berhubungan dengan proses belajar-mengajar; (3) Mahasiswa tidak tahu apa yang dimaksud masalah dalam penelitian; (4) Mahasiswa memaksakan judul yang dipilih kepada dosen pembimbing padahal judul itu kurang tepat; (5) Mahasiswa yang bimbingan hanya satu kali kemudian tidak pernah kembali lagi.

Data dalam penelitian ini diperoleh dengan teknik observasi, dan diukur menggunakan instrumen angket dengan skala likert. Angket disusun berdasarkan indikator-indikator yang diturunkan dari pengertian motivasi yang diberikan oleh Aritonang (2008), mencakup ketekunan belajar, keuletan belajar, dan minat dan ketajaman perhatian dalam belajar

Sebelum digunakan, angket telah dinyatakan valid melalui proses validasi konstruk dan validasi empiris. Angket dirancang dalam dua versi sesuai dengan kelompok sampel yang dibentuk. Secara umum indikator yang diukur dalam angket yang diberikan kepada kelompok control dan kelompok eksperimen adalah sama. Perbedaannya terletak pada redaksi dari butir pertanyaan. Pada angket untuk kelompok control, butir pertanyaan yang diberikan antara lain: (1) Saya selalu mendengarkan apersepsi dosen dengan baik; (2) Saya lebih senang berbicara sendiri dengan teman dan tidak mendengarkan pada saat dosen memberi apersepsi; (3) Saya senang jika dosen menggunakan apersepsi tradisional ketika menggunakan metode ceramah; (4) Apersepsi tradisional membuat saya tertarik untuk mengikui tahapan belajar selanjutnya. Sedangkan pada kelompok eksperimen butir pertanyaan yang digunakan antara lain: (1) Saya selalu mendengarkan apersepsi dosen dengan baik; (2) Saya lebih senang berbicara sendiri dengan teman dan tidak mendengarkan pada saat dosen memberi apersepsi; (3) Saya lebih senang jika dosen menggunakan apersepsi menggunakan stand-up comedy; (4) Apersepsi menggunakan stand-up comedy membuat saya tertarik untuk mengikuti tahapan belajar selanjutnya.

Data yang diperoleh dari angket, kemudian dianalisis menggunakan formula Independent sample t-test dengan bantuan software SPSS. Formula ini mensyaratkan dua data sampel harus homogen dan berdistribusi normal, sehingga 
sebelum melakukan uji-t terlebih dahulu melakukan uji homogenitas dua data sampel, dan uji normalitas masing-masing data sampel.

\section{HASIL DAN PEMBAHASAN}

Hasil analisis dengan bantuan program SPSS dideskripsikan dalam Tabel 1.

Tabel 1. Deskripsi Data Temuan Secara Umum

\begin{tabular}{lccccccc}
\multicolumn{7}{c}{ Descriptive Statistics } \\
\hline konrol & N & Range & Min. & Max. & Mean & Std. Deviation & Variance \\
eksperimen & 20 & 15.00 & 6.00 & 21.00 & 13.3000 & 3.77108 & 14.221 \\
Valid N (listwise) & 20 & 17.00 & 8.00 & 25.00 & 17.0000 & 5.28155 & 27.895 \\
\hline
\end{tabular}

Pada Tabel 1 terlihat bahwa skor motivasi terendah pada kelompok kontrol adalah 6 dan skor motivasi tertingginya adalah 21 dengan rata-rata 13,3. Sedangkan pada kelompok eksperimen skor motivasi terendahnya 8 dan skor motivasi tertingginya 25 dengan rata-rata 17 . Dari hasil tersebut terlihat bahwa secara umum rata-rata skor motivasi kelompok ekperimen lebih tinggi dibandingkan dengan skor motivasi kelompok kontrol. Skor motivasi terendah dan skor motivasi tertinggi kelompok eksperimen juga lebih besar daripada skor motivasi terendah dan skor motivasi tertinggi kelompok kontrol. Hal ini bisa diartikan bahwa kelompok eksperimen merasakan kelebihan apersepsi melalui stand-up comedy dengan metode ceramah daripada dengan menggunakan apersepsi tradisonal dengan metode yang sama.

Standar deviasi kelompok kontrol sebesar 3,77 (dibulatkan) dengan varian 14,221 dan standar deviasi kelompok eksperimen sebesar 5,28 (dibulatkan) dengan varian 27,895 . Standar deviasi dan varian adalah ukuran penyebaran titik data, sehingga dapat diartikan bahwa titik data pada kelompok eksperimen lebih tersebar di sekitar rata-rata dibandingkan dengan titik data pada kelompok kontrol. Jika pada kelompok kontrol, titik data terkumpul di sekitar rata-rata. Letak penyebaran titik data ini juga mencerminkan penyebaran titik data populasi. Artinya jika seluruh mahasiswa mendapatkan apersepsi melalui stand-up comedy dengan metode ceramah, maka sebagian besar dari mereka akan merasakan peningkatan motivasi belajar. Hasil ini dapat lebih dikuatkan dengan adanya analisis lanjutan untuk lebih menguatkan kesimpulan ini.

Untuk meyakinkan bahwa perbedaan rata-rata skor motivasi antara klompok kontrol dan kelompok eksperimen signifikan (nyata), peneliti melakukan uji-t sampel independen (independent sample t-test). Suatu data dapat dianalisis dengan formula uji-t sampel independen jika kedua kelompok data memiliki distribusi data yang normal dan varian kedua kelompok data bersifat homogen atau sejenis. Hasil uji normalitas dari data motivasi mahasiswa pada kelompok kontrol dan kelompok eksperimen adalah seperti pada Tabel 2. 
Tabel 2. Tets of Normality Kelompok Kontrol

Tests of Normality

\begin{tabular}{lcccccc}
\hline & \multicolumn{3}{c}{ Kolmogorov-Smirnova } & \multicolumn{3}{c}{ Shapiro-Wilk } \\
\cline { 2 - 7 } & Statistic & $d f$ & Sig. & Statistic & df & Sig. \\
\hline kontrol & .124 & 20 & $.200^{*}$ & .982 & 20 & .955 \\
\hline . Lilliefors Significance Correction \\
*. This is a lower bound of the true significance.
\end{tabular}

Hipotesis yang diuji dalam uji normalitas kelompok kontrol adalah:

Ho : Data motivasi kelompok kontrol berdistribusi normal.

$\mathrm{Ha}$ : Data motivasi kelompok kontrol tidak berdistribusi normal.

Kriteria pengambilan keputusan:

Jika nilai Sig. Shapiro-Wilk>0,05, maka Ho diterima dan menolak $\mathrm{Ha}$.

Jika nilai Sig. Shapiro-Wilk <0,05, maka Ho ditolak dan menerima $\mathrm{Ha}$.

Berdasarkan Tabel Test of Normality diketahui nilai Sig. Shapiro-Wilk yang diperoleh sebesar 0,955 >0,05. Keputusan yang diambil adalah menerima $\mathrm{Ho}$. Kesimpulannya, data motivasi mahasiswa pada kelompok kontrol berdistribusi normal. Berdistribusi normal artinya, sebagian besar responden kelompok kontrol memiliki skor motivasi yang dekat dengan skor rata-rata. Responden dengan skor motivasi terendah dan tertinggi jumlahnya paling sedikit dan semakin mendekati rata-rata semakin banyak.

Tabel 3. Tests of Normality Kelompok Eksperimen

Tests of Normality

\begin{tabular}{ccccccc}
\hline & \multicolumn{3}{c}{ Kolmogorov-Smirnov $^{\boldsymbol{a}}$} & \multicolumn{3}{c}{ Shapiro-Wilk } \\
\cline { 2 - 7 } & Statistic & $\boldsymbol{d f}$ & Sig. & Statistic & df & Sig. \\
\hline eksperimen & .128 & 20 & $.200^{*}$ & .946 & 20 & .314 \\
\hline
\end{tabular}

a. Lilliefors Significance Correction

*. This is a lower bound of the true significance.

Hipotesis yang diuji dalam uji normalitas kelompok eksperimen adalah:

Ho : Data motivasi mahasiswa pada kelompok eksperimen berdistribusi normal.

$\mathrm{Ha}$ : Data motivasi mahasiswa pada kelompok eksperimen tidak berdistribusi normal.

Kriteria pengambilan keputusan:

Jika nilai Sig. Shapiro - Wilk $>0,05$, maka Ho diterima dan menolak $\mathrm{Ha}$.

Jika nilai Sig. Shapiro-Wilk < 0,05, maka Ho ditolak dan menerima $\mathrm{Ha}$.

Berdasarkan Tabel Tests of Normality diketahui nilai Sig. Shapiro-Wilk sebesar 0,314 (> 0,05). Keputusan yang diambil adalah menerima $\mathrm{Ho}$. Kesimpulannya, data motivasi mahasiswa pada kelompok eksperimen berdistribusi normal. Berdistribusi normal artinya, sebagian besar responden kelompok eksperimen memiliki skor motivasi yang dekat dengan skor rata-rata. Responden 
dengan skor motivasi terendah dan tertinggi jumlannya paling sedikit dan semakin mendekati rata-rata semakin banyak.

Setelah diketahui bahwa kedua kelompok data memiliki distribusi normal, kemudian dilakukan uji homogenitas. Uji homogenitas mempersoalkan tentang varian dari dua data yang diperoleh. Dua buah data dikatakan homgen jika memiliki varian yang sejenis. Hipotesis yang diuji dalam uji homogenitas adalah:

Ho : Data motivasi mahasiswa pada kelompok kontrol dan kelompok eksperimen memiliki varian yang sama.

$\mathrm{Ha}$ : Data motivasi mahasiswa pada kelompok kontrol dan kelompok eksperimen memiliki varian yang tidak sama.

Kriteria pengambilan keputusannya:

Jika Sig. Levene's Test for Equality of Variances > 0,05, maka Ho diterima dan menolak $\mathrm{Ha}$.

Jika Sig. Levene's Test for Equality of Variance < 0,05, maka Ho ditolak dan menerima Ha. Hasil uji homogenitas dan Independent Sampel $t$-Test terlihat pada Tabel Independent Samples Test pada Tabel 4.

Tabel 4. Independent Samples Test

\begin{tabular}{|c|c|c|c|c|c|c|c|c|c|c|}
\hline & & \multicolumn{2}{|c|}{$\begin{array}{l}\text { Levene's Test } \\
\text { for Equality of } \\
\text { Variances }\end{array}$} & \multicolumn{7}{|c|}{ t-test for Equality of Meands } \\
\hline & & \multirow[t]{2}{*}{$F$} & \multirow[t]{2}{*}{ Sig. } & \multirow[t]{2}{*}{$t$} & \multirow[t]{2}{*}{$d f$} & \multirow{2}{*}{$\begin{array}{l}\text { Sig. (2- } \\
\text { tailed) }\end{array}$} & \multirow{2}{*}{$\begin{array}{c}\text { Means } \\
\text { Diferences }\end{array}$} & \multirow{2}{*}{$\begin{array}{l}\text { Std. Error } \\
\text { Diferences }\end{array}$} & \multicolumn{2}{|c|}{$\begin{array}{c}95 \% \text { Confidence } \\
\text { Interval of Diferences }\end{array}$} \\
\hline & & & & & & & & & Lower & Upper \\
\hline K. Eksperime & Equal variances & 3.285 & .078 & & 3 & .015 & - & 1.451 & - & -.7623 \\
\hline & assumed & & & 2.550 & 8 & & 3.7000 & 1 & 6.6377 & \\
\hline & Equal vauriances not & & & & 3 & .015 & & 1.451 & & -.7521 \\
\hline & assumed & & & 2.550 & 4.376 & & & 1 & 6.6479 & \\
\hline
\end{tabular}

Berdasarkan Tabel Independent Samples Test diketahui nilai Levene's Test for Equality of Variances sebesar 0,078 $(>0,05)$. Keputusan yang diambil adalah menerima Ho. Dengan demikian dapat disimpulkan bahwa data motivasi mahasiswa kelompok kontrol dan data motivasi mahasiswa kelompok eksperimen memiliki varian yang sejenis atau dikatakan homogen. Setelah kedua data dinyatakan berdistribusi normal dan homogen, maka dapat dilakukan uji-t sampel independen.

Hipotesis yang diuji dalam uji-t sampel Independen adalah:

Ho : Tidak ada perbedaan yang signifikan (nyata) antara rata-rata skor motivasi mahasiswa kelompok kontrol dan kelompok eksperimen.

$\mathrm{Ha}$ : Ada perbedaan yang signifikan (nyata) antara rata-rata skor motivasi mahasiswa kelompok kontrol dan kelompok eksperimen.

Kriteria pengambilan kesimpulannya:

Jika nilai Sig. (2-tailed) t-test for Equality of Means $>0,05$, maka Ho diterima dan menolak $\mathrm{Ha}$.

Jika nilai Sig. (2-tailed) t-test for Equality of Means < 0,05, maka Ho ditolak dan menerima $\mathrm{Ha}$. 
Berdasarkan Tabel Independen Sampel Test diperoleh nilai Sig. (2-tailed) $t$ test for Equality of Means sebesar 0,015 $(<0,05)$. Keputusan yang diambil adalah menolak Ho dan menerima Ha. Kesimpulannya, ada perbedaan yang signifikan (nyata) antara rata-rata skor motivasi mahasiswa kelompok kontrol dan kelompok eksperimen. Dengan kata lain, motivasi mahasiswa yang mendapat apersepsi melalui stand-up comedy dengan metode ceramah lebih tinggi dibandingkan dengan mahasiswa yang mendapat apersepsi tradisional dengan metode ceramah.

Hasil temuan ini sesuai dengan hasil penelitian yang dilakukan oleh Nurdiyana yang berjudul Persepsi Mahasiswa IImu Komunikasi Terhadap Tayangan Standup Comedy Kompas TV Sebagai Program Komedi Populer di Indonesia tahun 2017. Dalam penelitian tersebut disimpulkan bahwa 92,5\% Mahasiswa mengaku terhibur dengan hadirnya tayangan Standup Comedy. Ramdiana (2020:18-28) meneliti tentang apersepsi menggunakan cerita humor/lucu yang menunjukkan hasil bahwa motivasi belajar peserta didik meningkat setelah dilakukan apersepsi menggunakan cerita humor/lucu. Pada penelitian ini, para mahasiswa di kelas eksperimen merasa lebih termotivasi untuk menerima materi perkuliahan dengan apersepsi melalui standup comedy dibandingkan dengan kelas kontrol yang menggunakan apersepsi secara klasik.

\section{KESIMPULAN}

Berdasarkan hasil analisis data, dapat disimpulkan bahwa apersepsi pembelajaran melalui stand-up comedy dapat meningkatkan minat belajar mahasiswa dengan metode ceramah di STKIP PGRI Ponorogo secara signifikan. Dengan kata lain, apersepsi pembelajaran melalui stand-up comedy dapat menjadi salah satu alternatif cara penyampaian apersepsi kepada mahasiswa ketika dosen menerapkan metode pembelajaran ceramah. Dosen dapat menerapkan apersepsi melalui stand-up comedy untuk matakuliah-matakuliah terentu yang mengharuskan dosen menerapkan metode pembelajaran ceramah.

Ketika memutuskan untuk melakukan apersepsi pembelajaran melalui stand-up comedy, dosen harus memperiapkan naskah apersepsi secara matang sebelum pembelajaran dilakukan. Dosen juga harus memahami cara mengemas materi apersepsi dalam jokes dan set. Setelah naskah selesai dibuat, dosen juga perlu melakukan latihan delivery dan performance sebelum melakukan pembelajaran agar jokes, set, dan materi apersepsi yang telah disusun dapat tersampaikan dengan baik.

\section{REFERENSI}

Abdul, Rahman. P., Nila, R., \& Lisa. (2020). Komedi sebagai apersepsi dalam pembelajaran. Jurnal Kajian Teknologi Pendidikan, Vol. 3(2), 58-165.

Abuddin, Nata. (2011). Perspektif Islam tentang strategi pembelajaran. Jakarta: Kencana.

Aritonang, Keke T. (2008). Minat dan motivasi dalam meingkatkan hasil belajar siswa. Jurnal Pendidikan Penabur, No.10 Tahun ke-7 (2008) 11-21. 
Bruno, Pinto. David Marcal.,\& Sofia, G. Vas. (2013). Comunicating through humour:a project of stand-up comedy about science. Public Understanding of Science, 1-18. Diunduh dari: sagepub.co.uk/jurnalsPermissions.nav. (DOI:10.1177/0963662513511175).

Eriawati, N.P., I Wayan, S., \& Rai Sujanem. (2017). Strategi pembelajaran guru Fisika: Relevansinya dalam pengembangan kecerdasan emosional dan prestasi belajar siswa SMA. Jurnal Pendidikan Fisika Undiksha, Vol. 7(2), 97-108.

Gilstrap \& Martin. (1975). Curent strategies for teacher. California: Goodyear Publishing.

Hamalik, Oemar. (2011). Proses belajar mengaja. Jakarta: PT Bumi Aksara.

Hilman, Ramdiana. (2020). Apersepsi pembelajaran melalui cerita-cerita lucu untuk meningkatkan mutu pembelajaran dan profesionalisme guru dengan metode pembelajaran tutor sebaya di SMAN 21 Garut. Jurnal Kajian Teknologi Pendidikan, Vool. 3(1), 18-28.

Majid, Abdul. (2013). Strategi pembelajaran. Bandung: PT Remaja Rosdakarya.

Munif, Chatib. (2011). Gurunya manusia: Menjadikan semua anak istimewa dan semua anak juara. Bandung: Mizan Pustaka.

Nizar \& Hasibuan. (2011). Pendidik ideal. Depok: Prenada Media Grup.

Nugroho, P. (2012). Potret stand-up comedy. Yogyakarta: Pustaka Baru Press.

Nurdiyana. (2017). Persepsi Mahasiswa IImu Komunikasi Universitas Hasanudin terhadap tayangan standup comedy Kompas TV sebagai program komedi populer di Indonesia.

Petraki, Eleni., Huy Hoang Pham Nguyen. (2016). Do Asian EFL teacher use humor in the classroom? A case Study of Vietnamese EFL University teacher.Elsevier, 61, 98-109.

Sardiman. (2011). Interaksi dan motivasi belajar-mengajar. Jakarta: PT. Raja Grafindo Persada.

Shirli. (2012). Hubungan antara apersepsi dengan hasil belajar siswa pada pembelajaran IPS di Kelas V. Saung Guru. Diunduh dari: https://dokumen.tips/documents/proposal-skipsishirli2012hubungan-antaraapersepsi-dengan-hasil-belajar-siswa-pada-pembelajaran-ips-di-kelas-v55b942d943d3f.html.

Sriyono dkk. (1992). Teknik belajar mengajar dalam CBSA. Jakarta: PT Rineka Cipta.

Sukadi. (2006). Guru powerful guru masa depan. Bandung: Gramedia.

Uno, Hamzah B. (2011). Teori motivasi dan pengukurannya. Jakarta: Bumi Aksara. 